\title{
Atheromatous disease of the aorta and perioperative stroke
}

\author{
Nicholas D. Andersen, MD, ${ }^{\mathrm{a}}$ Stephen A. Hart, MD, ${ }^{\mathrm{c}, \mathrm{d}}$ Ganesh P. Devendra, MD, ${ }^{\mathrm{c}, \mathrm{d}}$ \\ Esther S. H. Kim, MD, MPH, ${ }^{\mathrm{f}}$ Douglas R. Johnston, MD, ${ }^{\mathrm{e}}$ Jacob N. Schroder, MD, ${ }^{\mathrm{a}}$ and \\ Richard A. Krasuski, MD ${ }^{\mathrm{b}}$
}

\footnotetext{
From the ${ }^{\mathrm{a}}$ Division of Cardiovascular and Thoracic Surgery, Department of Surgery, and ${ }^{\mathrm{b}}$ Division of Cardiology,

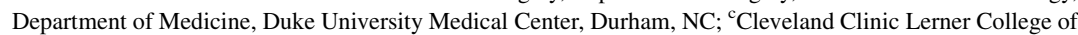
Medicine of Case Western Reserve University, Cleveland, Ohio; Departments of ${ }^{\mathrm{d}}$ Cardiovascular Medicine and ${ }^{\mathrm{e}}$ Cardiothoracic Surgery, Heart and Vascular Institute, Cleveland Clinic, Cleveland, Ohio; and ${ }^{\mathrm{f} D e p a r t m e n t}$ of Vascular Medicine, Vanderbilt Heart and Vascular Institute, Nashville, Tenn.

Received for publication March 8, 2017; revisions received July 24, 2017; accepted for publication Aug 24, 2017; available ahead of print Oct 4, 2017.

Address for reprints: Richard A. Krasuski, MD, Department of Cardiovascular Medicine, Duke University Health System, Durham, NC 27710 (E-mail: richard.krasuski@duke.edu).

J Thorac Cardiovasc Surg 2018;155:508-16

$0022-5223 / \$ 36.00$

Copyright $₫ 2017$ by The American Association for Thoracic Surgery https://doi.org/10.1016/j.jtcvs.2017.08.132
}

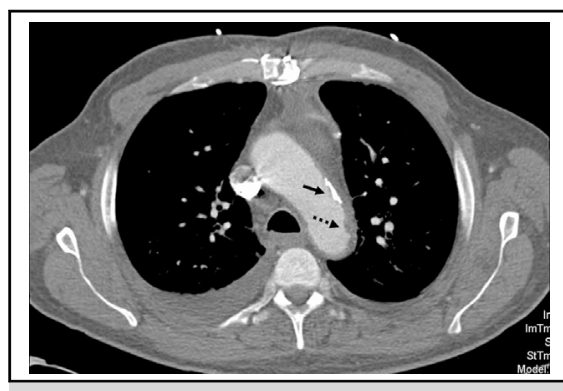

Can we reduce the risk of perioperative stroke from aortic atheroma?

\section{Central Message}

In this paper, we review the current understanding of atheromatous disease of the aorta and strategies for perioperative stroke prevention in patients undergoing cardiac surgery.

Perspective
Atheromatous disease of the aorta occurs
frequently in patients undergoing cardiac sur-
gery and poses a significant risk for periopera-
tive stroke. The risk of stroke from aortic
atheroma may be reduced with an increased un-
derstanding of atheroma characteristics and
pathogenesis, risk factor modification, imaging
identification, alterations in surgical technique,
and use of embolic protection devices.

See Editorial Commentaries pages 517 and 518.

See Editorial page 507.

\section{STROKE AFTER CARDIAC SURGERY}

Despite continued improvements in patient outcomes after cardiac surgery, stroke remains one of the most feared and devastating complications of cardiac surgery and is estimated to occur in $1.2 \%$ to $1.6 \%$ of patients undergoing coronary artery bypass grafting $(\mathrm{CABG}) .{ }^{1-3}$ The incidence of stroke increases for other common cardiac surgical procedures, and contemporary studies from the Society of Thoracic Surgeons database have reported perioperative stroke rates of $1.4 \%$ for mitral valve repair, ${ }^{4} 1.5 \%$ for aortic valve replacement, ${ }^{5} 2.1 \%$ for mitral valve replacement, ${ }^{4}$ and $6.6 \%$ for proximal aorta replacement. ${ }^{6}$ Stroke remains one of the most important contributors to postoperative morbidity and mortality and has been associated with 5year survival rates of $60 \%$ or less. ${ }^{1,7}$ In addition, stroke after cardiac surgery has been demonstrated to cause increased hospital mortality, increased duration of hospitalization, and may contribute up to 4 billion dollars in additional health care-related costs per year. ${ }^{1,7,8}$

\section{ATHEROMATOUS DISEASE OF THE AORTA AND THE RISK OF STROKE}

Aortic atherosclerosis is linked pathogenically with chronic inflammatory responses to injury of the arterial smooth muscle and endothelium and is morphologically characterized by the formation of intimal plaque and lipid deposition, fibrous proliferation, calcification, and necrosis. ${ }^{9}$ The presence of aortic atheroma has been well established as an independent predictor of central nervous system (CNS) events in the general population and is as important as traditional contributors to embolism, such as left atrial thrombus, carotid lesions, and atrial fibrillation. ${ }^{10}$ Although surgery itself is a risk factor for stroke, the additional contribution of aortic atherosclerotic disease in patients undergoing cardiac surgical intervention cannot be understated. There are a number of intuitive mechanisms by which cardiac surgical operations may induce embolization: aortic manipulation, cannulation, crossclamping, and side clamping, among others. Accordingly, many studies have demonstrated a link between aortic atherosclerosis and postoperative CNS injury after cardiac surgery. ${ }^{1,7,8}$ In 1996, The Multicenter Study of Perioperative Ischemia reported the results of a 
prospective multicenter analysis of 2108 patients undergoing elective CABG surgery and found that proximal aortic atheroma was the strongest independent predictor of stroke, with an odds ratio of $4.52 .{ }^{8}$ Since then, multiple other studies have confirmed a 3- to 4-fold increased risk of perioperative stroke after cardiac surgery in patients with atheroma or calcification of the proximal aorta. ${ }^{1,7,11}$

\section{ATHEROMA TOPOGRAPHY}

Atheromatous disease is a regional process explained in part by variations in hemodynamics (Figure 1), ${ }^{12}$ and the risk of stroke after cardiac surgery may be altered by a plaque's location. In a meticulous analysis of stroke risk related to proximal aorta plaque location, van der Linden and colleagues ${ }^{11}$ demonstrated that the precise location of proximal aorta atheroma significantly altered the degree of stroke risk. The authors developed a topographic odds ratio map for late stroke based on disease located in 12 different segments of the ascending aorta. Although disease located in the proximal ascending aorta and along the anterior surface carried no increased risk, plaque located in the distal ascending aorta and the lesser curvature carried up to

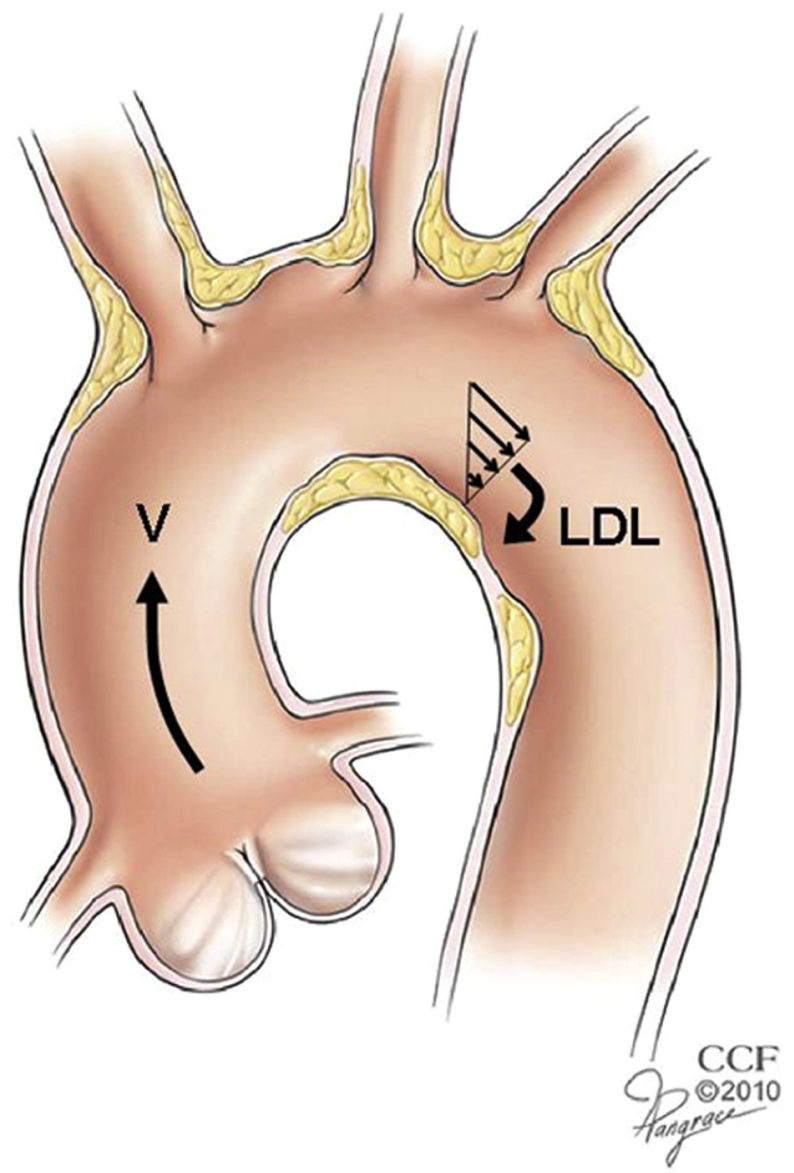

FIGURE 1. As blood velocity decreases near the wall of the aorta, LDL deposition increases. $V$, Velocity; $L D L$, low-density lipoprotein. a 5-fold greater risk of late stroke. In multivariate analysis, they demonstrated that the extent of atheromatous disease was a strong predictor of late stroke but that plaque in key "high-risk" zones, including the distal ascending aorta and the lesser curvature, were far more predictive.

Although it remains unknown why atheroma in these highrisk zones was more malignant than plaque in the proximal or anterior ascending aorta, the authors speculated that increased flow velocity in these regions may dislodge loose atherosclerotic material, which may have been slightly mobilized by earlier surgical maneuvers. ${ }^{11}$ It should be emphasized that these high-risk zones in the distal ascending aorta and lesser curvature are the most difficult to assess by manual palpation or transesophageal echocardiography (TEE). The authors estimated that patients with such high-risk anatomy comprised up to $10 \%$ of the cardiac surgical population.

\section{ATHEROMA CHARACTERISTICS}

Careful research has resulted in improved characterization of pathologic plaques of the aorta. In addition to plaque location — plaque thickness, morphology, and mobility independently influence the likelihood of early and late stroke. The standard cut-off for "at-risk" plaque thickness has been established at $4 \mathrm{~mm}$ or greater, with plaques $4 \mathrm{~mm}$ or greater associated with a 4-fold increased likelihood of stroke and a linear increase in stroke seen with increasing plaque thickness. ${ }^{10}$ Similar to plaques in the coronary arteries, plaque instability is likely an even stronger risk factor for rupture and embolic stroke than plaque thickness. Vulnerable aortic plaques have been identified echocardiographically by the presence of increased hypoechoiety, calcification, and ulceration. Lastly, several studies have shown that mobile plaques (Figure 2) represent an extremely high-risk lesion and may increase the likelihood of stroke several-fold compared with nonmobile plaques. ${ }^{13}$

\section{STROKE PREVENTION IN THE PERIOPERATIVE SETTING}

Stroke in the perioperative setting is prevalent, but some events may be preventable. ${ }^{14}$ The risk of stroke is multifactorial and can be divided into modifiable and nonmodifiable risk factors. Nonmodifiable risk factors include age, sex, socioeconomic status, and genetics. ${ }^{15,16}$ Modifiable risk factors include comorbid disease, the type and technique of surgery, perioperative management, the experience of the surgical team, and the complexity of the surgical case.

The first step in preventing perioperative stroke is to optimize comorbid diseases. After diet, exercise, and glucose control have been implemented, appropriate therapy with lipid-lowering medications can help reduce global atheroma burden. It has been shown that statins reduce the size of atherosclerotic plaques, and a retrospective matched-pairs analysis demonstrated that statin therapy resulted in a $17 \%$ reduction in the absolute risk of stroke among patients 


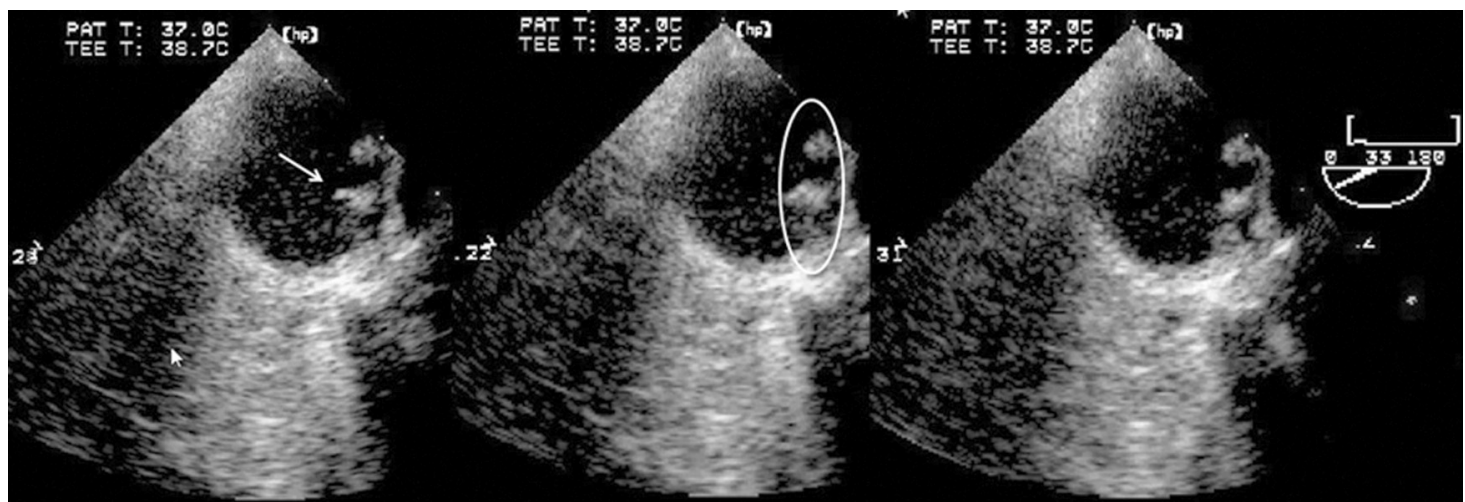

FIGURE 2. Intraoperative transesophageal echocardiographic images from a patient with a complex aortic atheroma (oval). These 3 time-lag short-axis images of the transverse aortic arch demonstrate the mobile nature of a portion of the lesion (arrow).

with severe atheromatous disease of the aorta. ${ }^{17}$ However, randomized controlled trials have produced conflicting results on the ability of immediate preoperative statin therapy to reduce the risk of stroke after cardiac surgery. ${ }^{18}$ The use of antiplatelet or anticoagulation medications is similarly controversial. Aspirin therapy administered within 48 hours of CABG surgery was shown to reduce the rate of stroke in a large, prospective study. ${ }^{19}$ A small number of retrospective studies also found benefit to oral anticoagulation with warfarin in patients with mobile aortic plaques, ${ }^{13}$ although

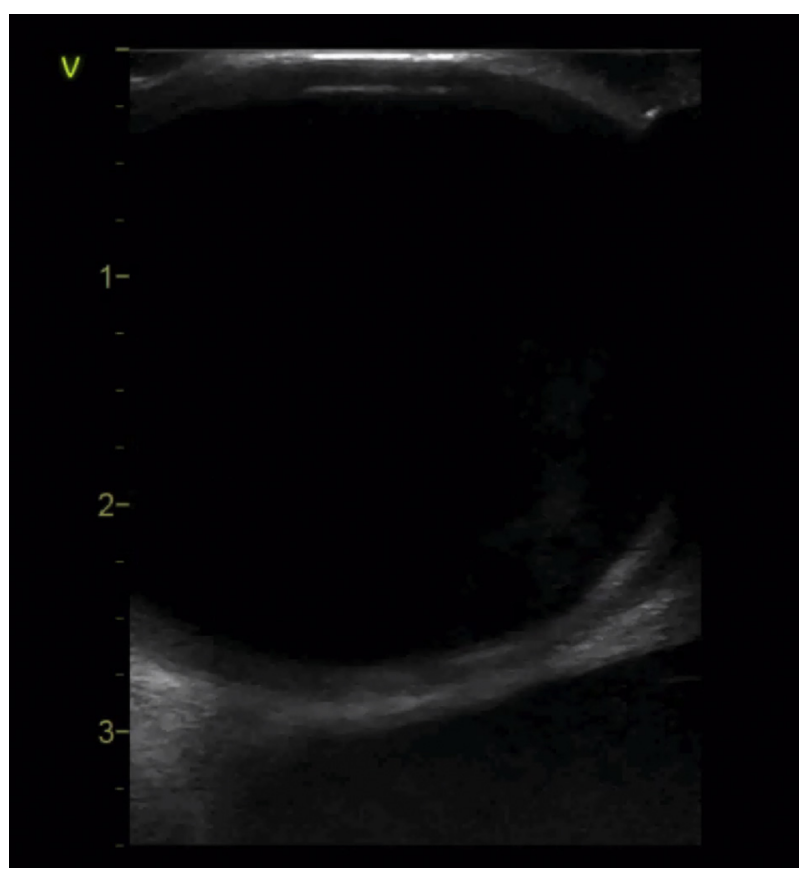

VIDEO 1. Case 1: short-axis view (best viewed on repeat with Windows Media Player). Intraoperative epiaortic ultrasound scanning demonstrating normal ascending aorta before aortic cannulation in a 60-year-old woman undergoing coronary artery bypass grafting. Video available at: http:// www.jtcvsonline.org/article/S0022-5223(17)31908-6/fulltext. these findings have not been replicated or reproduced uniformly in patients undergoing heart surgery.

\section{IMAGING MODALITIES}

The traditional gold standard for detecting aortic atheroma is epiaortic ultrasound (EAU), which is performed by positioning an ultrasound transducer directly on the aorta after sternotomy (Videos 1 and 2). ${ }^{20}$ Manual palpation and TEE (Figure 2) also have been used to detect aortic atheroma but have consistently underperformed when compared with EAU. Manual palpation of the aorta occurs

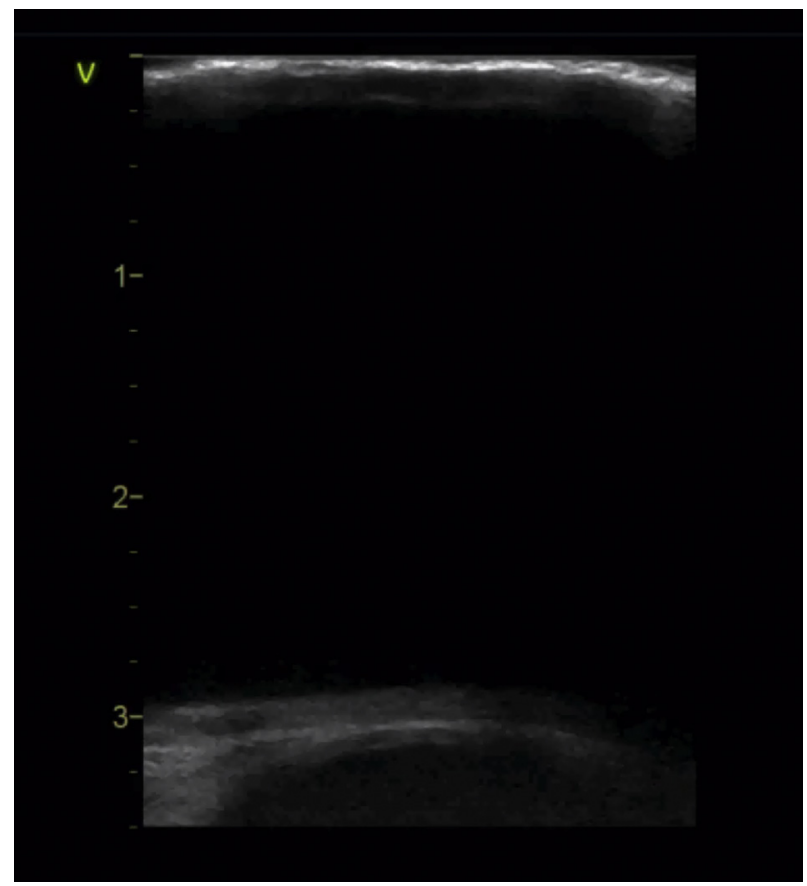

VIDEO 2. Case 1: long-axis view (best viewed on repeat with Windows Media Player). Video available at: http://www.jtcvsonline.org/article/ S0022-5223(17)31908-6/fulltext. 


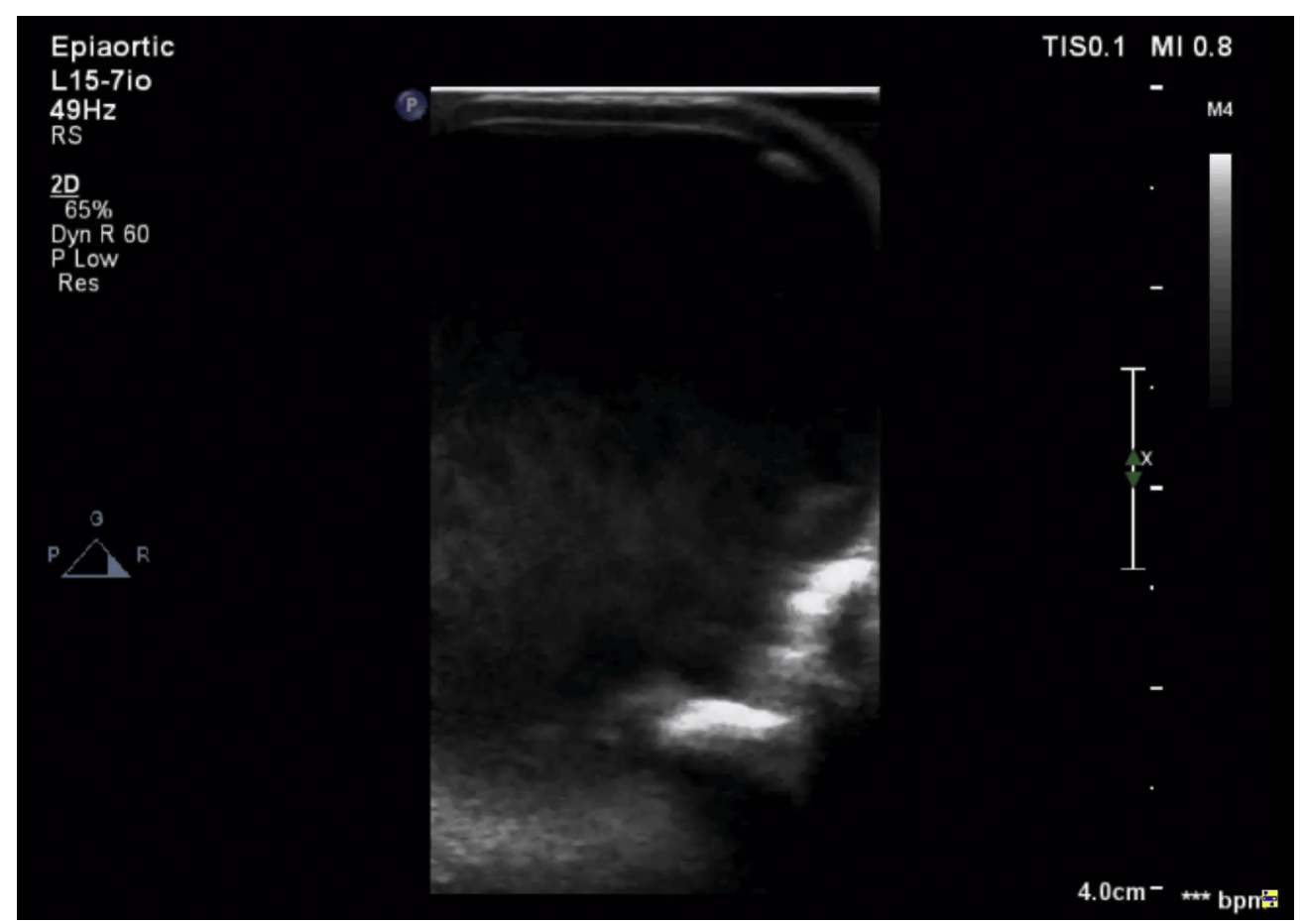

VIDEO 3. Case 2: short-axis view (best viewed on repeat with Windows Media Player). Epiaortic ultrasound scanning identified a large shelf of calcified posterior plaque in the distal ascending aorta/proximal arch in a 77-year-old woman undergoing coronary artery bypass grafting and aortic valve replacement. Ultrasound was used to identify and select sites for aortic cannulation, crossclamping, aortotomy, and proximal anastomoses in areas of unaffected ascending aorta well away from the posterior shelf. Video available at: http://www.jtcvsonline.org/article/S0022-5223(17)31908-6/fulltext.

in most cardiac surgeries requiring cardiopulmonary bypass, and TEE frequently is used to assess cardiac structure and function before and after a procedure, making these modalities very convenient. However, manual palpation may cause plaques to embolize, and adequate visualization of the highest-risk zones in the ascending aorta and aortic arch are limited with TEE because of tracheal shadow. ${ }^{20}$ Studies have estimated that the sensitivity of manual palpation for detecting atheroma may be as low as $25 \% .{ }^{21}$ The sensitivity of TEE is, unfortunately, only marginally better. ${ }^{21}$ Minor disadvantages of EAU are that it lengthens surgical time, requires expertise and training in its use, and it can only provide information intraoperatively after committing to an incision. For these reasons, EAU has not been adopted on a large scale. Recent guidelines set forth by the American Society of Echocardiography and the Society of Cardiovascular Anesthesiologists attempt to standardize intraoperative EAU examinations and provide rationale for its routine use in cardiovascular surgeries. ${ }^{20}$

Data supporting the use of EAU to identify at-risk patients have come largely from retrospective studies. The first study to explore the impact of EAU on postoperative stroke found that aortic scanning before CABG resulted in modification of the planned surgical procedure in $31 \%$ of patients (Videos 3 and 4). Those with the most severe disease suffered the greatest postoperative mortality but did not have increased incidence of stroke in the early postoperative period. $^{22}$ The authors suggested that EAU appropriately identified patients at high risk for postoperative stroke and led to alterations in surgical strategy that may have prevented stroke in the greatest-risk patients. A more recent cohort series demonstrated that routine EAU led to altered surgical strategy in a much more modest number $(4.1 \%)$ of patients. ${ }^{23}$ A careful study examining perioperative outcomes found that EAU led to a significantly increased number of modified surgical plans compared with manual palpation alone, but embolic load to the brain measured by transcranial Doppler and postoperative stroke scores remained unchanged. ${ }^{24}$ In a much larger cohort study, Yamaguchi and colleagues ${ }^{25}$ demonstrated that EAU resulted in 0 postoperative strokes among 909 consecutive patients undergoing CABG. If ascending aortic atheroma at least $3 \mathrm{~mm}$ thick was detected, the surgical strategy was altered to allow for a "no-touch" approach.

It should be noted that newer imaging technologies, such as A-view TEE, magnetic resonance imaging (MRI), and computed tomography (CT; Figure 3) demonstrate growing potential as screening modalities but currently lack the evidence base of EAU. A-view TEE uses a fluid-filled balloon catheter placed in the trachea to image the "blind spot" of 


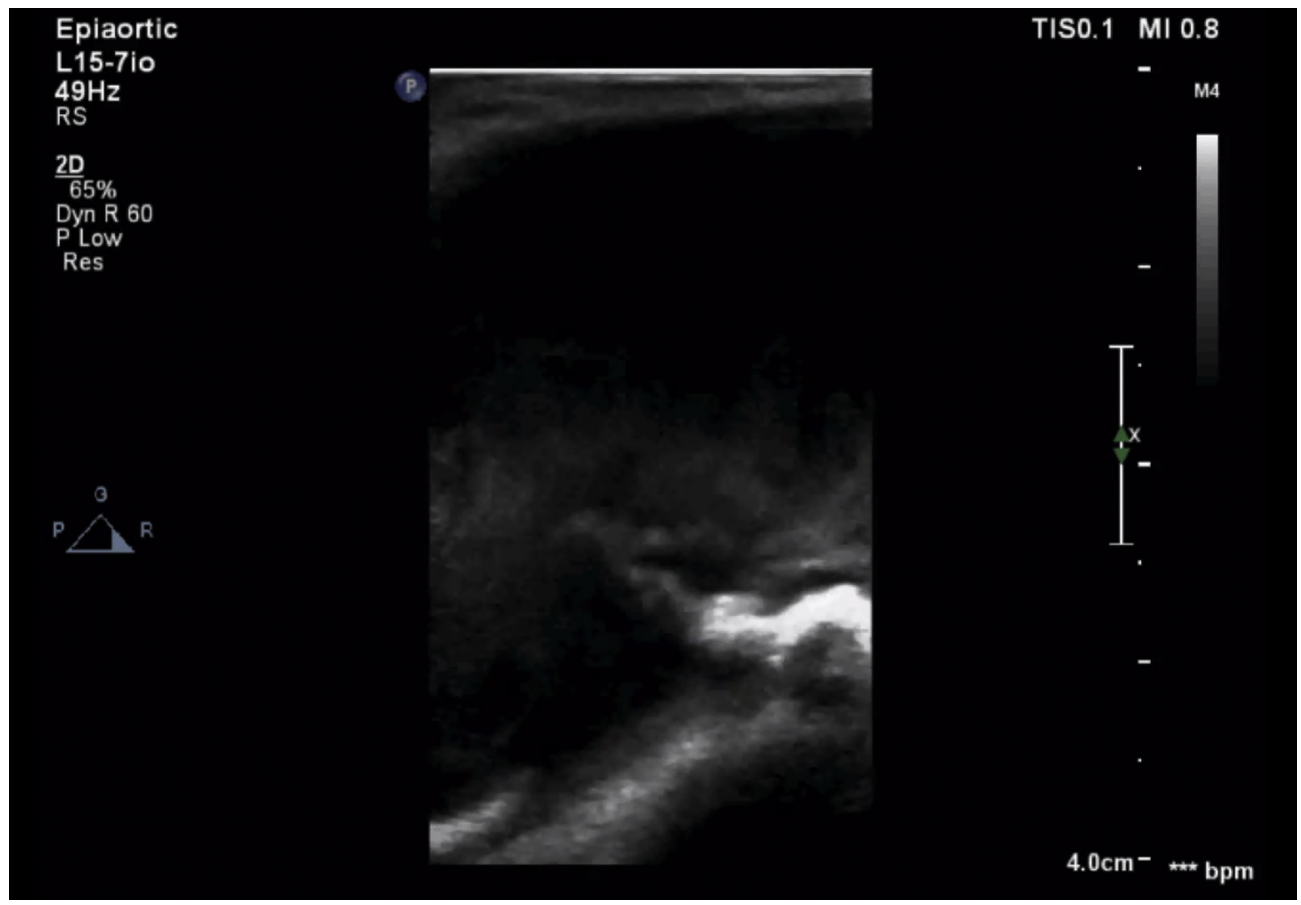

VIDEO 4. Case 2: long-axis view (best viewed on repeat with Windows Media Player). Video available at: http://www.jtcvsonline.org/article/S00225223(17)31908-6/fulltext.

the aorta that normally is concealed by the tracheal shadow. Although this technique has shown promise in small studies, widespread adoption has not occurred, possibly due to the need for additional training, the cost of the Aview catheter (Cordatec Inc, Zoersel, Belgium), and concerns with tracheal instrumentation. ${ }^{26}$ The advantage of CT or MRI modalities is that surgical decision making may take place far in advance of surgery, allowing for a

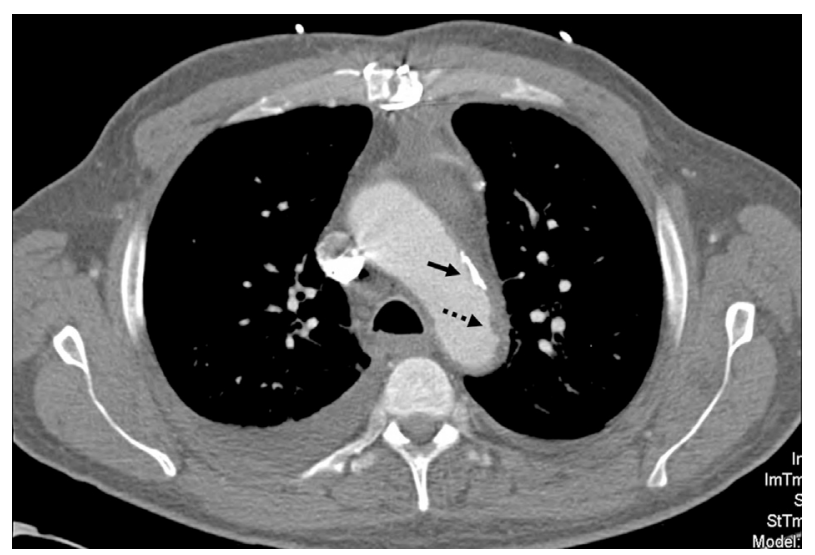

FIGURE 3. Contrast-enhanced helical computed tomography of the chest in a patient awaiting cardiothoracic surgery. This image demonstrates significant atheromatous plaque in the aortic arch, both with (solid arrow) and without (dashed arrow) calcification. change in surgical plan or procedure before incision, as well as reduced operative time. Disadvantages include cost and radiation exposure.

Although one study found that CT was inferior to EAU in detecting aortic atheroma, ${ }^{27}$ a more recent meta-analysis found that preoperative $\mathrm{CT}$ imaging significantly reduced the rate of stroke in patients undergoing primary and reoperative heart surgery, ${ }^{28}$ and additional randomized controlled trials of preoperative CT imaging are currently underway. ${ }^{29}$ Although these studies do not prove superiority of CT imaging over EAU, it is likely that preoperative CT imaging will become the preferred screening modality for many practitioners as these techniques are optimized and accumulate evidence. Whether these preoperative imaging studies should be applied to all patients or only select high-risk patients with risk factors for atherosclerosis also warrants additional study.

\section{SURGICAL TECHNIQUES}

In addition to improvements in screening methods, research also has focused on variations in surgical techniques designed to prevent stroke in patients with atheromatous disease of the aorta. Aortic atherectomy was first reported by Culliford and colleagues,${ }^{30}$ and this technique has been used successfully in patients with extensive disease but has not been widely used for patients with mild or moderate disease. Graft reconstruction of the ascending 


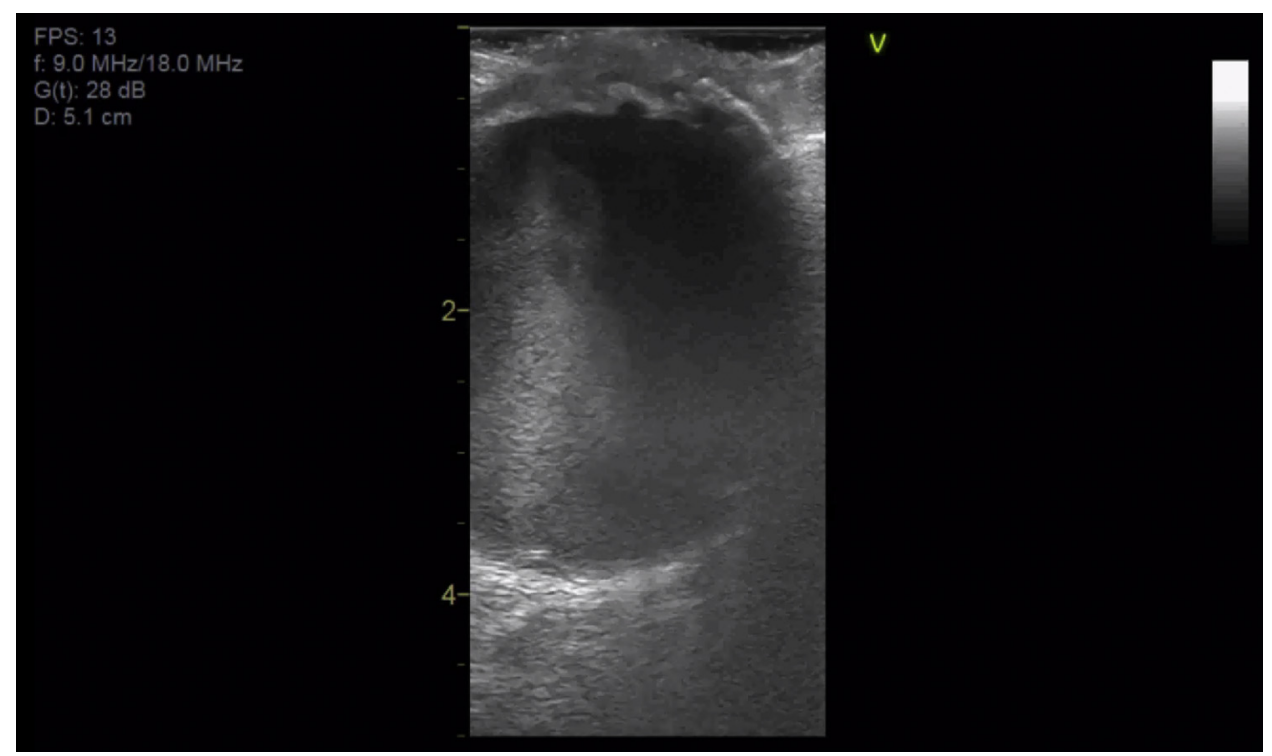

VIDEO 5. Case 3: short-axis view (best viewed on repeat with Windows Media Player). Epiaortic ultrasound scanning demonstrated diffuse calcifications in the anterior and posterior ascending aorta in a 75-year-old man undergoing CABG. The surgical plan was altered to avoid aortic cannulation or crossclamping. The patient underwent on-pump beating-heart CABG via right axillary artery cannulation. The left internal mammary artery was grafted to the left anterior descending artery, and a saphenous vein was sequenced to the obtuse marginal and posterior descending artery distal targets, allowing for a single, proximal, aortic anastomosis performed with a clampless facilitating device. Video available at: http://www.jtcvsonline.org/article/S0022-5223(17)31908-6/fulltext.

aorta and aortic arch also has been studied as a stroke prevention technique and has been shown to be efficacious in patients undergoing cardiac surgery, especially aortic valve surgery. ${ }^{31}$
Instead of removing diseased segments from the aorta, many investigators have tried to avoid atherosclerotic plaques altogether. Techniques such as off-pump coronary artery bypass grafting (OPCABG), alternate cannulation

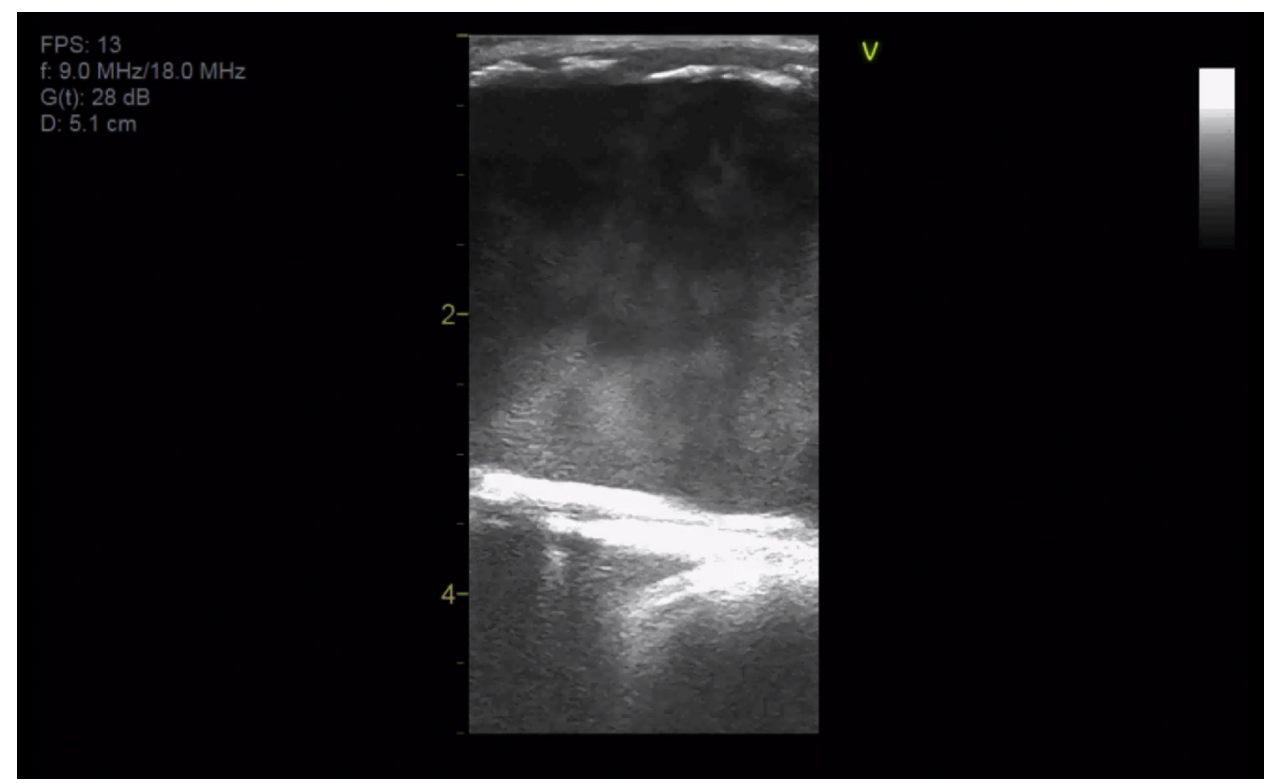

VIDEO 6. Case 3: long-axis view (best viewed on repeat with Windows Media Player). Video available at: http://www.jtcvsonline.org/article/S00225223(17)31908-6/fulltext. 

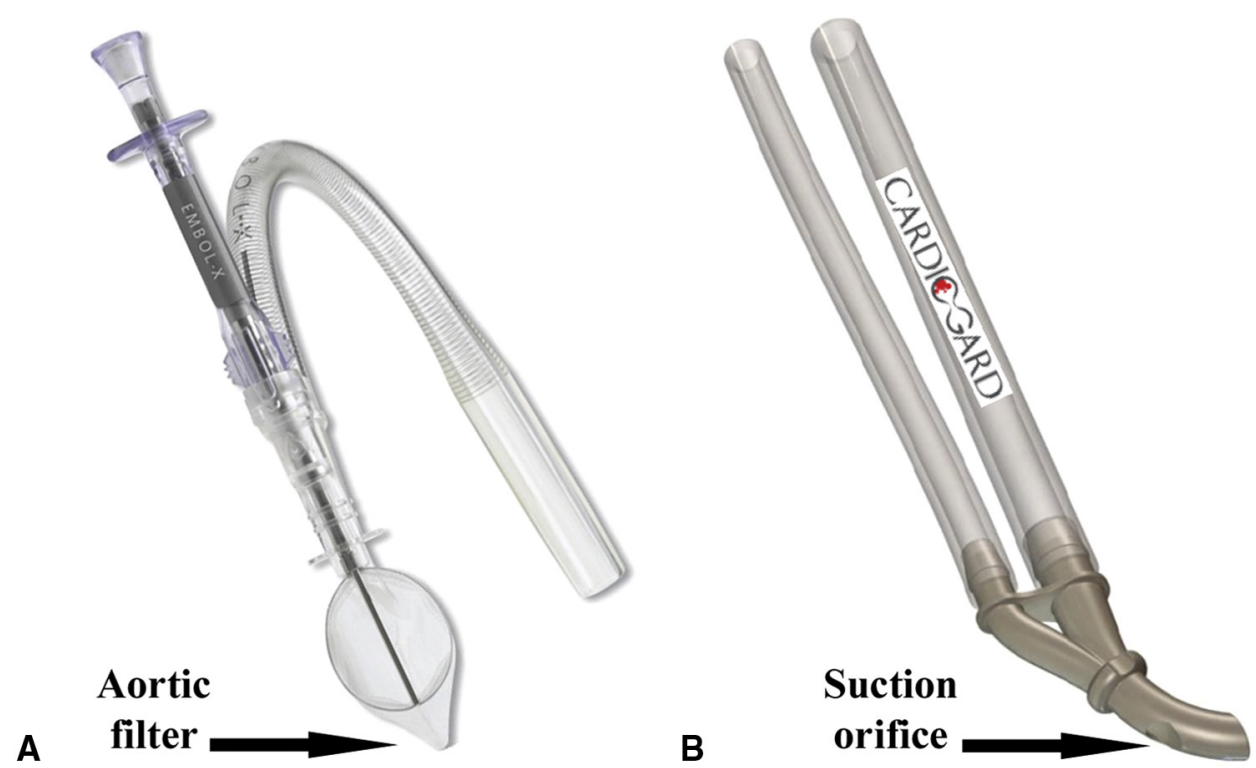

FIGURE 4. Commercially available embolic protection devices. A, The Embol-X intra-aortic filtration system (Edwards Lifesciences). B, The CardioGard Embolic Protection cannula (CardioGard Medical).

sites, use of single aortic crossclamp techniques, and use of fibrillatory arrest have proliferated in an effort to reduce perioperative stroke. Some groups have found that use of a single crossclamp reduces perioperative stroke, but a recent meta-analysis did not confirm these findings. ${ }^{32,33}$ Alternate bypass cannulation sites also have been shown to reduce stroke, especially when used in concert with EAU to identify disease-free regions of the aorta (Videos 5 and 6). ${ }^{34,35}$ Many studies have demonstrated considerable benefit to OPCABG, and this technique also has been shown to be safe and further prevent stroke in the greatest-risk patients. ${ }^{36}$ Metaanalyses have confirmed the benefits of OPCABG in the short term, but long-term outcomes have been less conclusive. ${ }^{37,38}$

\section{EMERGING TECHNOLOGY: EMBOLIC PROTECTION DEVICES}

To date, 2 devices intended to reduce cerebral emboli during cardiac surgery have received approval from the Food and Drug Administration and remain the focus of on-going comparative effectiveness studies. Both devices represent modified aortic cannulas with technology for protecting the brain from showered emboli. The Embol-X intra-aortic filtration system (Edwards Lifesciences, Irvine, Calif; Figure 4, $A$ ) is an aortic cannula with a collapsible filter that is deployed in the ascending aorta before crossclamp removal and captures embolic material released from the aorta or heart during reperfusion. In a large, multicenter, randomized controlled trial of 1289 patients undergoing isolated $\mathrm{CABG}$, aortic valve replacement (AVR), or mitral valve replacement, particulate emboli were captured successfully in $97 \%$ of patients who underwent surgery with the Embol-X device. There were no differences in adverse events, including death, stroke, or renal failure, between treated and control patients. However, a subgroup analysis of patients at moderate-to-high risk for postoperative morbidity or mortality demonstrated a reduced risk of renal failure with the Embol-X device. ${ }^{39}$

The CardioGard Embolic Protection cannula (CardioGard Medical, Or Yehuda, Israel; Figure 4, $B$ ) is a modified aortic cannula with a suction orifice at the tip intended to extract solid and gaseous emboli from the ascending aorta during all phases of cardiopulmonary bypass. In a small, multicenter, randomized, controlled trial in which authors compared the CardioGard cannula $(\mathrm{n}=27)$ with control patients $(n=24)$ undergoing AVR with or without CABG, results showed a reduced volume of new brain lesions detected by diffusion-weighted MRI in treated versus control patients, as well as a lower proportion of patients $(41 \%$ vs $66 \%)$ with any new brain lesion detected by diffusion-weighted MRI. However, there were no differences in clinical end-points between groups, including stroke, death, major adverse events, or Mini-Mental State Examination scores. ${ }^{40}$

Based on these data, a National Heart Lung and Blood Institute-sponsored Cardiothoracic Surgical Trials Network clinical trial (\#NCT02389894) randomized 383 participants undergoing AVR with or without CABG to surgery using the Embol-X, CardioGard, or control cannula in a $1: 1: 1$ ratio. $^{41}$ The primary endpoint was freedom from clinical or radiographic CNS 
infarction at $7 \pm 3$ days after the procedure. Results demonstrated that neither embolic protection device led to improvements in freedom from clinical or radiographic CNS infarction, clinical stroke, the overall volume of CNS infarcts by MRI, or neurocognitive outcomes assessed at 90 days. However, both devices successfully captured embolic debris in most patients and led to reductions in postoperative delirium and large volume infarcts. Despite not meeting the primary end-point of reduced perioperative stroke, further study aims to determine whether there are long-term neurocognitive benefits from embolic capture. ${ }^{42}$

\section{CONCLUSIONS}

Atheromatous disease of the aorta occurs frequently in patients undergoing cardiac surgery and poses a significant risk for perioperative stroke. Certain atheroma characteristics such as location, thickness, mobility, and ulceration have been shown to pose the greatest risk of stroke. Preoperative or intraoperative identification of aortic atheroma may reduce the risk of stroke by allowing for alterations to the surgical plan. The gold-standard for detecting aortic atheroma intraoperatively is EAU, and its use has been shown to decrease the incidence of stroke in the perioperative setting, especially among the greatest-risk patients. Preoperative CT imaging is gaining in popularity and can successfully identify atheromatous disease and allow for alteration of the surgical plan before the operating theater. Novel embolic protection devices successfully captured embolic debris in the majority of patients but failed to reduce the rate of perioperative stroke in a recent randomized clinical trial. These devices remain the focus of ongoing study and may benefit from further technologic optimization.

\section{Conflict of Interest Statement}

The senior authors (Drs Johnston, Schroder, Krasuski) previously have published on surgical stroke prevention and participated in the National Heart, Lung, and Blood Institutesponsored Cardiothoracic Surgical Trials Network clinical trial (NCT02389894) studying embolic protection devices during cardiac surgery. Dr Krasuski reports having served as a consultant for Actelion and has received research funding from Actelion, St Jude Medical, and Edwards Life Sciences. All other authors have nothing to disclose with regard to commercial support.

\section{References}

1. Filsoufi F, Rahmanian PB, Castillo JG, Bronster D, Adams DH. Incidence, topography, predictors and long-term survival after stroke in patients undergoing coronary artery bypass grafting. Ann Thorac Surg. 2008;85:862-70.

2. Selnes OA, Gottesman RF, Grega MA, Baumgartner WA, Zeger SL, McKhann GM. Cognitive and neurologic outcomes after coronary-artery bypass surgery. N Engl J Med. 2012;366:250-7.
3. ElBardissi AW, Aranki SF, Sheng S, O'Brien SM, Greenberg CC, Gammie JS. Trends in isolated coronary artery bypass grafting: an analysis of the Society of Thoracic Surgeons adult cardiac surgery database. J Thorac Cardiovasc Surg. 2012;143:273-81.

4. O'Brien SM, Shahian DM, Filardo G, Ferraris VA, Haan CK, Rich JB, et al. The Society of Thoracic Surgeons 2008 cardiac surgery risk models: part 2-isolated valve surgery. Ann Thorac Surg. 2009;88(1 suppl):S23-42.

5. Thourani VH, Suri RM, Gunter RL, Sheng S, O'Brien SM, Ailawadi G, et al. Contemporary real-world outcomes of surgical aortic valve replacement in 141,905 low-risk, intermediate-risk, and high-risk patients. Ann Thorac Surg. 2015;99:55-61.

6. Williams JB, Peterson ED, Zhao Y, O'Brien SM, Andersen ND, Miller DC, et al. Contemporary results for proximal aortic replacement in North America. J Am Coll Cardiol. 2012;60:1156-62.

7. Filsoufi F, Rahmanian PB, Castillo JG, Bronster D, Adams DH. Incidence, imaging analysis, and early and late outcomes of stroke after cardiac valve operation. Am J Cardiol. 2008;101:1472-8.

8. Roach GW, Kanchuger M, Mangano CM, Newman M, Nussmeier N, Wolman R, et al. Adverse cerebral outcomes after coronary bypass surgery. Multicenter Study of Perioperative Ischemia Research Group and the Ischemia Research and Education Foundation Investigators. N Engl J Med. 1996;335:1857-63.

9. Falk E. Pathogenesis of atherosclerosis. J Am Coll Cardiol. 2006;47(8 suppl): C7-12.

10. French Study of Aortic Plaques in Stroke Group, Amarenco P, Cohen A, Hommel M, Moulin T, Leys D, Bousser M-G. Atherosclerotic disease of the aortic arch as a risk factor for recurrent ischemic stroke. N Engl J Med. 1996; 334:1216-21.

11. van der Linden J, Bergman P, Hadjinikolaou L. The topography of aortic atherosclerosis enhances its precision as a predictor of stroke. Ann Thorac Surg. 2007; $83: 2087-92$

12. Soulis J, Giannoglou G, Dimitrakopoulou M, Papaioannou V, Logothetides S, Mikhailidis D. Influence of oscillating flow on LDL transport and wall shear stress in the normal aortic arch. Open Cardiovasc Med J. 2009;3:128-42.

13. Kronzon I, Tunick PA. Aortic atherosclerotic disease and stroke. Circulation 2006;114:63-75.

14. Douglas JM Jr, Spaniol SE. A multimodal approach to the prevention of postoperative stroke in patients undergoing coronary artery bypass surgery. Am J Surg. 2009; 197:587-90.

15. Hogue CW Jr, Barzilai B, Pieper KS, Coombs LP, DeLong ER, Kouchoukos NT, et al. Sex differences in neurological outcomes and mortality after cardiac surgery: a society of thoracic surgery national database report. Circulation. 2001; 103:2133-7.

16. Agabiti N, Cesaroni G, Picciotto S, Bisanti L, Caranci N, Costa G, et al. The as sociation of socioeconomic disadvantage with postoperative complications after major elective cardiovascular surgery. J Epidemiol Community Health. 2008;62: $882-9$.

17. Tunick PA, Nayar AC, Goodkin GM, Mirchandani S, Francescone S, Rosenzweig BP, et al. Effect of treatment on the incidence of stroke and other emboli in 519 patients with severe thoracic aortic plaque. Am J Cardiol. 2002;90:1320-5.

18. Putzu A, Capelli B, Belletti A, Cassina T, Ferrari E, Gallo M, et al. Perioperative statin therapy in cardiac surgery: a meta-analysis of randomized controlled trials. Crit Care. 2016;20:395.

19. Mangano DT. Multicenter Study of Perioperative Ischemia Research Group. Aspirin and mortality from coronary bypass surgery. N Engl J Med. 2002;347: 1309-17.

20. Glas KE, Swaminathan M, Reeves ST, Shanewise JS, Rubenson D, Smith PK, et al. Guidelines for the performance of a comprehensive intraoperative epiaortic ultrasonographic examination: recommendations of the American Society of Echocardiography and the Society of Cardiovascular Anesthesiologists; endorsed by the Society of Thoracic Surgeons. Anesth Analg. 2008;106:1376-84.

21. Suvarna S, Smith A, Stygall J, Kolvecar S, Walesby R, Harrison M, et al. An in traoperative assessment of the ascending aorta: a comparison of digital palpation, transesophageal echocardiography, and epiaortic ultrasonography. J Cardiothorac Vasc Anesth. 2007;21:805-9.

22. Hangler HB, Nagele G, Danzmayr M, Mueller L, Ruttmann E, Laufer G, et al Modification of surgical technique for ascending aortic atherosclerosis: impact on stroke reduction in coronary artery bypass grafting. J Thorac Cardiovasc Surg. 2003;126:391-400.

23. Rosenberger P, Shernan SK, Loffler M, Shekar PS, Fox JA, Tuli JK, et al. The influence of epiaortic ultrasonography on intraoperative surgical management in 6051 cardiac surgical patients. Ann Thorac Surg. 2008;85:548-53. 
24. Djaiani G, Ali M, Borger MA, Woo A, Carroll J, Feindel C, et al. Epiaortic scanning modifies planned intraoperative surgical management but not cerebral embolic load during coronary artery bypass surgery. Anesth Analg. 2008;106: 1611-8.

25. Yamaguchi A, Adachi H, Tanaka M, Ino T. Efficacy of intraoperative epiaortic ultrasound scanning for preventing stroke after coronary artery bypass surgery. Ann Thorac Cardiovasc Surg. 2009; 15:98-104.

26. Nierich AP, van Zaane B, Buhre WF, Coddens J, Spanjersberg AJ, Moons KG Visualization of the distal ascending aorta with A-Mode transesophageal echocardiography. J Cardiothorac Vasc Anesth. 2008;22:766-73.

27. Bergman P, van der Linden J, Forsberg K, Ohman M. Preoperative computed tomography or intraoperative epiaortic ultrasound for the diagnosis of atherosclerosis of the ascending aorta? Heart Surg Forum. 2004; 7:E245-9; discussion E249.

28. den Harder AM, de Heer LM, Meijer RC, Das M, Krestin GP, Maessen JG, et al Effect of computed tomography before cardiac surgery on surgical strategy, mortality and stroke. Eur J Radiol. 2016;85:744-50.

29. den Harder AM, de Heer LM, Maurovich-Horvat P, Merkely B, de Jong PA, Das M, et al. Ultra low-dose chest ct with iterative reconstructions as an alternative to conventional chest x-ray prior to heart surgery (CRICKET study): rationale and design of a multicenter randomized trial. J Cardiovasc Comput Tomogr. 2016;10:242-5.

30. Culliford AT, Colvin SB, Rohrer K, Baumann FG, Spencer FC. The atherosclerotic ascending aorta and transverse arch: a new technique to prevent cerebral injury during bypass: experience with 13 patients. Ann Thorac Surg. 1986;41:27-35.

31. Zingone B, Rauber E, Gatti G, Pappalardo A, Benussi B, Forti G, et al. Diagnosis and management of severe atherosclerosis of the ascending aorta and aortic arch during cardiac surgery: focus on aortic replacement. Eur J Cardiothorac Surg. 2007:31:990-7.

32. Hammon JW, Stump DA, Butterworth JF, Moody DM, Rorie K, Deal DD, et al. Single crossclamp improves 6-month cognitive outcome in high-risk coronary bypass patients: the effect of reduced aortic manipulation. J Thorac Cardiovasc Surg. 2006;131:114-21.
33. Raja SG, Navaratnarajah M, Fida N, Kitchlu CS. For patients undergoing coronary artery bypass grafting at higher risk of stroke is the single cross-clamp technique of benefit in reducing the incidence of stroke? Interact Cardiovasc Thorac Surg. 2008;7:500-3.

34. Kokotsakit J, Lazopoulos G, Milonakis M, Athanasiadis G, Romana K, Skouteli E, et al. Right axillary artery cannulation for surgical management of the hostile ascending aorta. Tex Heart Inst J. 2005;32:189-93; discussion 5 .

35. Smith PK. Predicting and preventing adverse neurologic outcomes with cardiac surgery. J Card Surg. 2006;21(suppl 1):S15-9.

36. Sharony R, Bizekis CS, Kanchuger M, Galloway AC, Saunders PC, Applebaum R, et al. Off-pump coronary artery bypass grafting reduces mortality and stroke in patients with atheromatous aortas: a case control study. Circulation. 2003;108(suppl 1):II15-20.

37. Kuss O, von Salviati B, Borgermann J. Off-pump versus on-pump coronary artery bypass grafting: a systematic review and meta-analysis of propensity score analyses. J Thorac Cardiovasc Surg. 2010;140:829-35. 835.e1-13.

38. Feng ZZ, Shi J, Zhao XW, Xu ZF. Meta-analysis of on-pump and off-pump coronary arterial revascularization. Ann Thorac Surg. 2009;87:757-65.

39. Banbury MK, Kouchoukos NT, Allen KB, Slaughter MS, Weissman NJ, Berry GJ, et al. Emboli capture using the Embol-X intraaortic filter in cardiac surgery: a multicentered randomized trial of 1,289 patients. Ann Thorac Surg. 2003; 76:508-15; discussion 515 .

40. Bolotin G, Huber CH, Shani L, Mohr FW, Carrel TP, Borger MA, et al. Novel emboli protection system during cardiac surgery: a multi-center, randomized, clinical trial. Ann Thorac Surg. 2014;98:1627-33; discussion 1633-34.

41. CTSN Network. Neuroprotection in Patients Undergoing Aortic Valve Replacement. Available at: http://www.ctsurgerynet.org/NPAbstract.html. Accessed January 30, 2017.

42. Cerebral Embolic Protection in Patients Undergoing Surgical Aortic Valve Replacement (SAVR). Available at: http://clinicaltrialresults.org/Slides/ ACC2017/Cerebralembolicprotection_Mack.pdf. Accessed May 17, 2017. 